\title{
Megabacteriose em emas (Rhea americana) no Estado do Rio Grande do Sul, Brasil
}

\author{
Megabacteriosis in Rhea americana in the State of Rio Grande do Sul, Brazil
}

\author{
Stefanie Dickel Segabinazi ${ }^{1}$ Maristela Lovato Flôres ${ }^{2}$ Glaucia Denise Kommers ${ }^{3}$ \\ Aleverson da Silva Barcelos ${ }^{1}$ Dalvan Carlo Veit ${ }^{4}$ Rosângela Dariva Eltz ${ }^{5}$
} \begin{abstract}
Com o objetivo de avaliar as causas de mortalidade
de filhotes de ema de uma propriedade, pesquisou-se
megabactéria em esfregaços de moelas de oito emas, corados
pelo método de Gram, associado a exame histopatológico. Os
exames foram positivos para megabactéria em quatro emas. A
confirmação de megabacteriose em emas no Rio Grande do Sul
é de grande importância, pois a enfermidade pode gerar grandes
perdas econômicas. Salienta-se a necessidade de maiores
investigações nos diferentes criatórios, tendo em vista a elevada
mortalidade inicial dos filhotes relatada pelos criadores, podendo
ser a megabacteriose uma das causas. RESUMO
\end{abstract}

Palavras-chave: ema, Rhea americana, megabactéria, patologia aviária.

\section{ABSTRACT}

To evaluate the causes of high mortality in great rhea chicks, we performed a study searching for megabacteria in Gram stained smear of eight great rhea gizzards, also examined by histopathology. The results were positive in four great rhea. The confirmation of megabacteriosis in great rhea in Rio Grande do Sul State, Brazil, has great importance, because the disease could be causing severe economic losses. We emphasize the need of further studies in the different great rhea farms to investigate the possible role of megabacteriosis in the high mortality of great rhea chicks.

Key words: great rhea, Rhea americana, megabacteria, avian pathology.
A megabacteriose ou gastrite por megabactéria é considerada uma doença fatal em várias espécies de aves, tendo sido descrita em periquitos australianos e ingleses, agapornis, cacatuas, canários, codornas japonesas, galinhas, avestruzes e emas (HUCHZERMEYER et al., 1993; GERLACH, 2001; BORIS \& HUCHZERMEYER, 2002). No Brasil, WERTHER et al. (2000) encontraram megabactéria durante exames pós morte em canários, agapornis e periquitos.

Segundo GERLACH (2001), a megabactéria é uma estrutura bacilar, grande, Gram positiva, medindo $1-5 \mathrm{~mm}$ de largura por $20-90 \mathrm{~mm}$ de comprimento. Recentemente, TOMASZEWSKI et al. (2003), ao realizarem a análise filogenética da megabactéria das aves, a classificaram como um fungo ascomiceto anamórfico e sugeriram que seja chamada de Macrorhabdus ornithogaster.

O presente trabalho objetivou relatar a primeira ocorrência no Brasil de megabacteriose em filhotes de ema, no Estado do Rio Grande do Sul.

Foram encaminhados ao Laboratório Central de Diagnóstico de Patologias Aviárias (LCDPA) da Universidade Federal de Santa Maria, oito filhotes de ema (com idades de 15 dias a 4 meses) provenientes de uma criação comercial, localizada na

\footnotetext{
${ }^{1}$ Médico Veterinário, Mestrando, Laboratório Central de Diagnóstico de Patologias Aviárias (LCDPA), Departamento de Medicina Veterinária Preventiva (DMVP), Centro de Ciências Rurais (CCR), Universidade Federal de Santa Maria (UFSM), RS, Bolsista Capes.

${ }^{2}$ Médico Veterinário, Professor Adjunto Doutor, LCDPA, DMVP, CCR, UFSM, 97105-900, Santa Maria, RS. E-mail: patoaves@ ccr.ufsm.br. Autor para correspondência.

${ }^{3}$ Médico Veterinário, Professor Adjunto PhD, Departamento de Patologia, Seção de Patologia Veterinária, Centro de Ciências da Saúde, UFSM.

${ }^{4}$ Acadêmico de Medicina Veterinária, Estagiário LCDPA, DMVP, CCR, UFSM.

${ }^{5}$ Técnico de Laboratório, DMVP, CCR, UFSM.
} 
Região Central do Estado do Rio Grande do Sul. Os sinais clínicos eram de emagrecimento progressivo (embora continuassem alimentando-se), fraqueza, atraso no desenvolvimento e morte.

Durante a necropsia, em quatro aves, observou-se palidez da mucosa oral e da superfície externa do proventrículo e moela, repleta de conteúdo fibroso. Os intestinos continham alimento mal digerido e de coloração escura e exaustão da gordura corporal inclusive a coronária. Na retirada do conteúdo da moela e limpeza da membrana coilina, notou-se a presença de úlceras, que em alguns casos, perfuravam a membrana coilina, chegando à camada mucosa da moela. As outras quatro aves apresentavam somente sinais de infecção bacteriana do saco da gema, confirmada pelo isolamento de Escherichia coli. Os sinais clínicos e lesões de necropsia apresentados pelas aves concordam com HUCHZERMEYER et al. (1993) e BORIS \& HUCHZERMEYER (2002) em avestruzes e emas com megabacteriose.

Esfregaços das moelas afetadas foram corados pelo método de Gram e observadas em microscopia óptica, em 1.000x. Verificaram-se diversas estruturas semelhantes a grandes bacilos Gram positivos, com dimensões de 20 a $90 \mathrm{~mm}$ de comprimento e 1 a $5 \mathrm{~mm}$ de diâmetro de largura, condizentes com a descrição da megabactéria feita por HUCHZERMEYER et al. (1993) (Figura 1A).

Seções histológicas de porções de moela, membrana coilina e proventrículo foram coradas pelo método do PAS. Na membrana coilina, foram observadas múltiplas estruturas em forma de bastonetes longos, dispostos paralelamente, com medidas de 20 a $90 \mathrm{~mm}$ de comprimento e 1 a $5 \mathrm{~mm}$ de diâmetro, PAS positivos (Figura 1B). Nos proventrículos, não havia alteração histológica. $\mathrm{Na}$ mucosa da moela, havia focos discretos de necrose circundados por infiltrado leve de heterófilos e linfócitos. Estas lesões são compatíveis com o apresentado por HUCHZERMEYER et al. (1993) em infecções por megabactéria.

Pode-se comprovar, através do quadro clínico, esfregaços de moela e exame histopatológico das lesões, ocorrência de megabacteriose em filhotes de emas no Brasil. Este achado tem relevância, pois a megabactéria pode estar envolvida, junto a outros agentes, como causa da alta mortalidade inicial de filhotes, já observada em algumas criações de emas no Estado do Rio Grande do Sul.

\section{REFERÊNCIAS BIBLIOGRÁFICAS}

BORIS, M.; HUCHZERMEYER, F.W. Megabacteriosis como causa de alta mortalidad en charabones de ñandú (Rhea americana): primer diagnóstico en Uruguay. Revista oficial de la Sociedad de Medicina veterinaria del Uruguay, Montevideo, v.37, n.149, p.09-12, 2002.

GERLACH, H. Megabacteriosis. Seminars in Avian and Exotic Pet Medicine, Philadelphia, v.10, n.1, p.12-19, 2001.

HUCHZERMEYER, F.W.; HENTON, M.M.; KEFFEN, R.H. High mortality associated with megabacteriosis of proventriculus and gizzard in ostrich chicks. Veterinary Record, London, v.133, n.6, p.143-144, 1993.

TOMASZEWSKI, E.K. et al. Phylogenetic analysis indicates the 'megabacterium' of birds is a novel anamorphic ascomycetous yeast, Macrorhabdus ornithogaster gen. nov.,sp.nov. Capturado em 15 maio 2003. Online. Disponível em http://www.sgm.ac.uk/PiP/ijsem02514.pdf

WERTHER, K. et al. Megabacteriosis occurrence in budgerigars, canaries and lovebirds in Ribeirão Preto region - São Paulo State - Brazil. Revista Brasileira de Ciência Avícola, Campinas, v.2, n.2, p183-187, 2000.

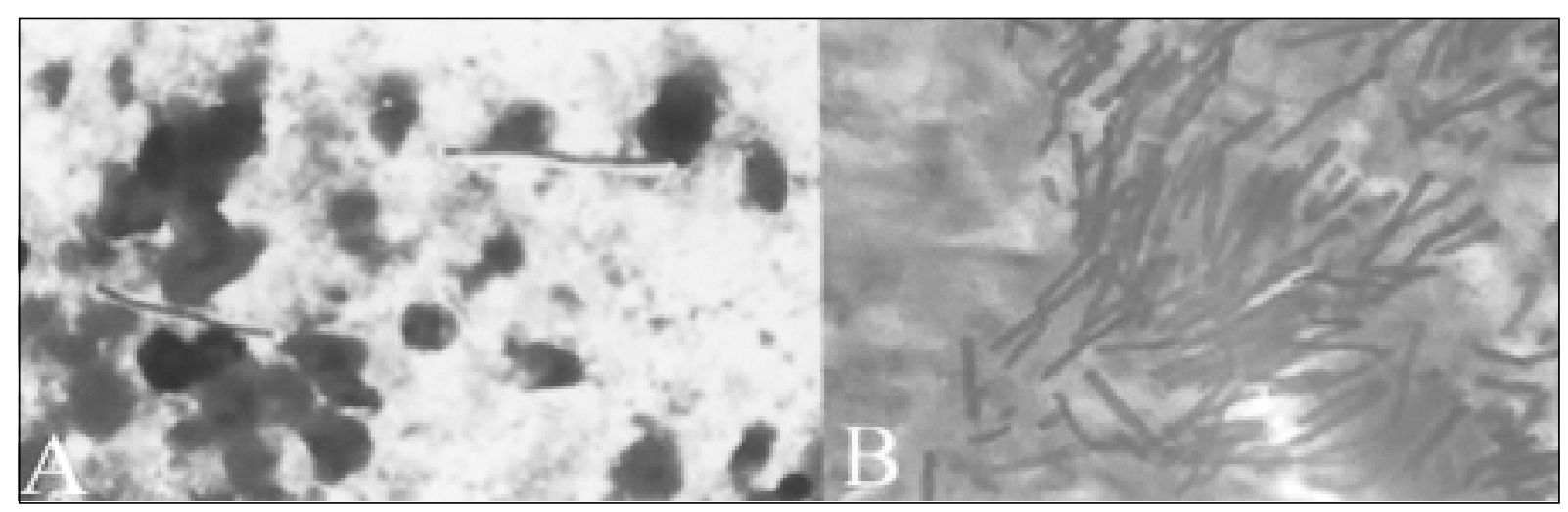

Figura 1A - Megabactérias em esfregaço de moela de ema (Rhea americana) corado por Gram, 1.000x. B- Corte histológico de membrana coilina de ema (Rhea americana) corado por PAS com presença de megabactérias dispostas paralelamente, 400x. 